\title{
8
}

\section{Microtremor HVSR Study of Site Effects in Bursa City (Northern Marmara Region, Turkey)}

\author{
Elcin Gok ${ }^{1}$ and Orhan Polat ${ }^{2}$ \\ ${ }^{1}$ Dokuz Eylul University, Earthquake Research and Implementation Center, Izmir \\ ${ }^{2}$ Dokuz Eylul University, Engineering Faculty, Department of Geophysics, Izmir
}

Turkey

\section{Introduction}

Local site effects are one of the most important aspects in the assessment of seismic hazard. Local site response can be investigated by empirical and theoretical methods. Theoretical methods allow a detail analysis of the parameters considered in the evaluation; however, they require information of the geological structure (Dravinski et al., 1996). Empirical methods are based on seismic records on sites with different geological condition from which relative amplitudes and dominant periods may be determined directly. This approach requires of a large number of earthquakes. In regions with low seismicity, it would be necessary to wait for a long time to obtain a complete data set. For this reason, the use of ambient seismic noise is becoming popular as an alternative (Bard, 1998).

Recording and analyzing ambient noise is simple. A few minutes of microtremor data are usually sufficient. Microtremors are present continuously in time and space. A single threecomponent station is the only instrument required. Routine spectral techniques can be easily applied to estimate the dominant frequency of vibration of the sedimantary structure. These frequencies of vibration are closely related to the physical features of the site under study, i.e., layer thicknesses, densities and wave velocities. Estimates of these frequencies are useful to constrain the physical properties at a given site.

The Nakamura technique (Nakamura, 1989), based on the horizontal to vertical spectral ratio (HVSR), has been commonly used to estimate the site effects. Later it has been extended to both weak motions (Ohmachi et al., 1991; Field \& Jacob, 1993, 1995); and strong motions (Lermo \& Chavez-Garcia, 1994; Theodulidis \& Bard, 1995; Suzuki et al., 1995). Lermo \& Chavez-Garcia (1993) applied this technique to estimate the empirical transfer function from the intense S-wave part of a small sample of earthquake records obtained in three cities of Mexico. Their results showed that the HVSR can estimate the dominant frequency at a site based on earthquake data.

Suzuki et al. (1995), using both microtremor and strong motion data in Hokkaido, Japan, showed that the dominant frequency obtained from HVSR was in good agreement with the predominant frequency estimated from the thickness of an alluvial layer. Lermo \& Chavez-Garcia (1993) compared transfer functions computed using the Haskell method agreement with the HVSR. Lermo \& Chavez-Garcia (1994) verified that the underlying 
assumptions of Nakamura's technique are consistent with the propagation of Rayleigh waves.

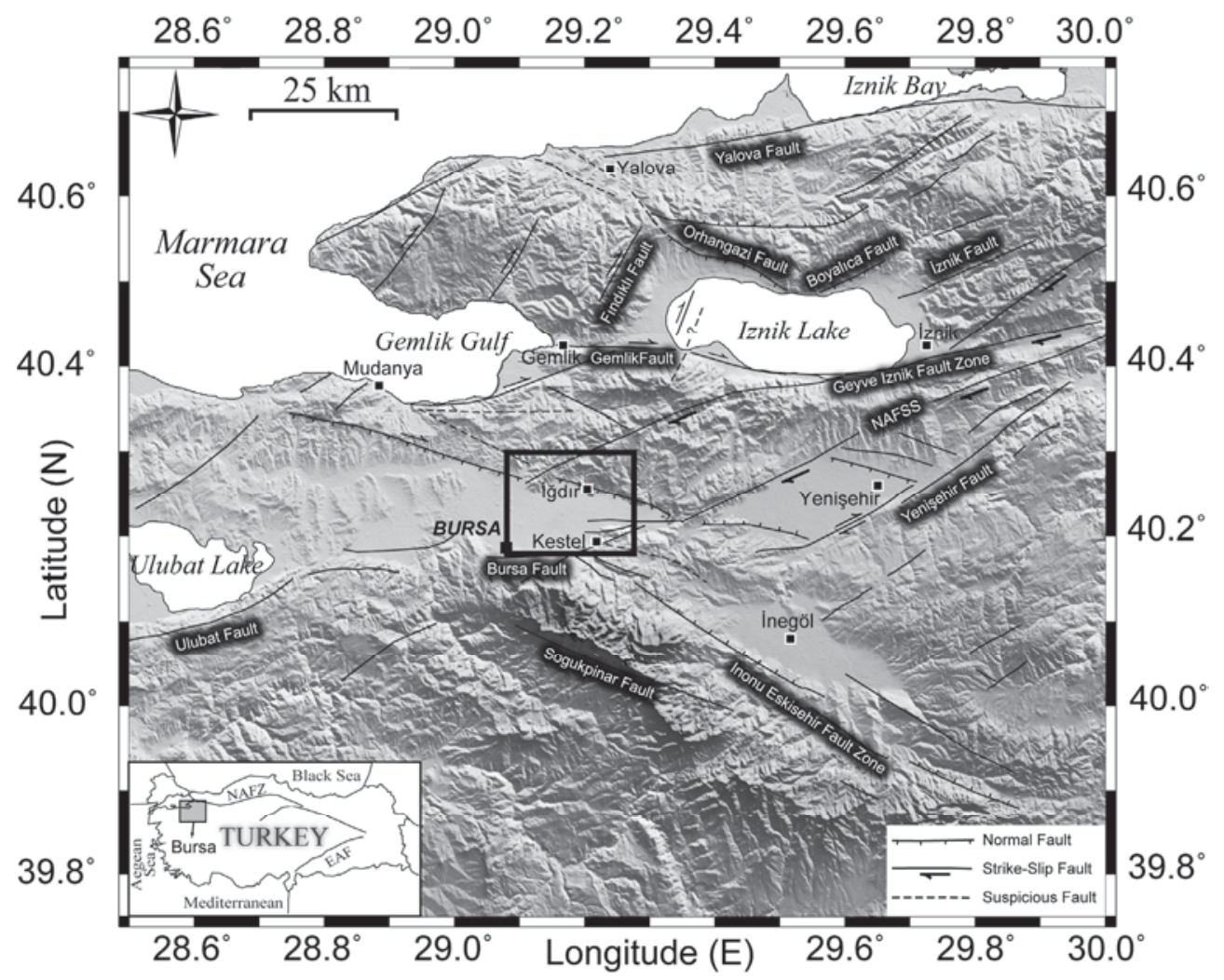

Fig. 1. Map of Bursa. The box indicates the study area. NAFZ: North Anatolian Fault Zone, NAFSS: Southern strand of the North Anatolian Fault Zone, EAF: East Anatolian Fault Zone.

\section{Tectonic and geological setting}

The region of study is surrounded by many active faults; Gemlik Fault (GF), Geyve-Iznik Fault Zone (GIFZ), Yenişehir Fault, Bursa Fault (BF), Inonu-Eskisehir Fault Zone (IEFZ). The main lithological units in the vicinity of Bursa are Quaternary alluvial deposits and Neogene basement rocks. The thickness of the Quaternary deposits is larger than $300 \mathrm{~m}$ where those are as Neogene units vary from 50 to 200m. in Bursa basin (Imbach 1997; Topal et al., 2003). South of Bursa, Paleozoic and methamorfic units are present. The simplified geological map of the study area, modified from MTA (General Directory of Mineral Research and Exploration), is shown in Figure 2.

Bursa city is located in the southern Marmara Region, characterised by significant historical and instrumental seismicity (Figure 1). Two strong earthquakes, with maximum intensities $X$ and IX EMS-98, occurred in 1855. Seismicity is related with the activity of southern branch of the NAFZ. 


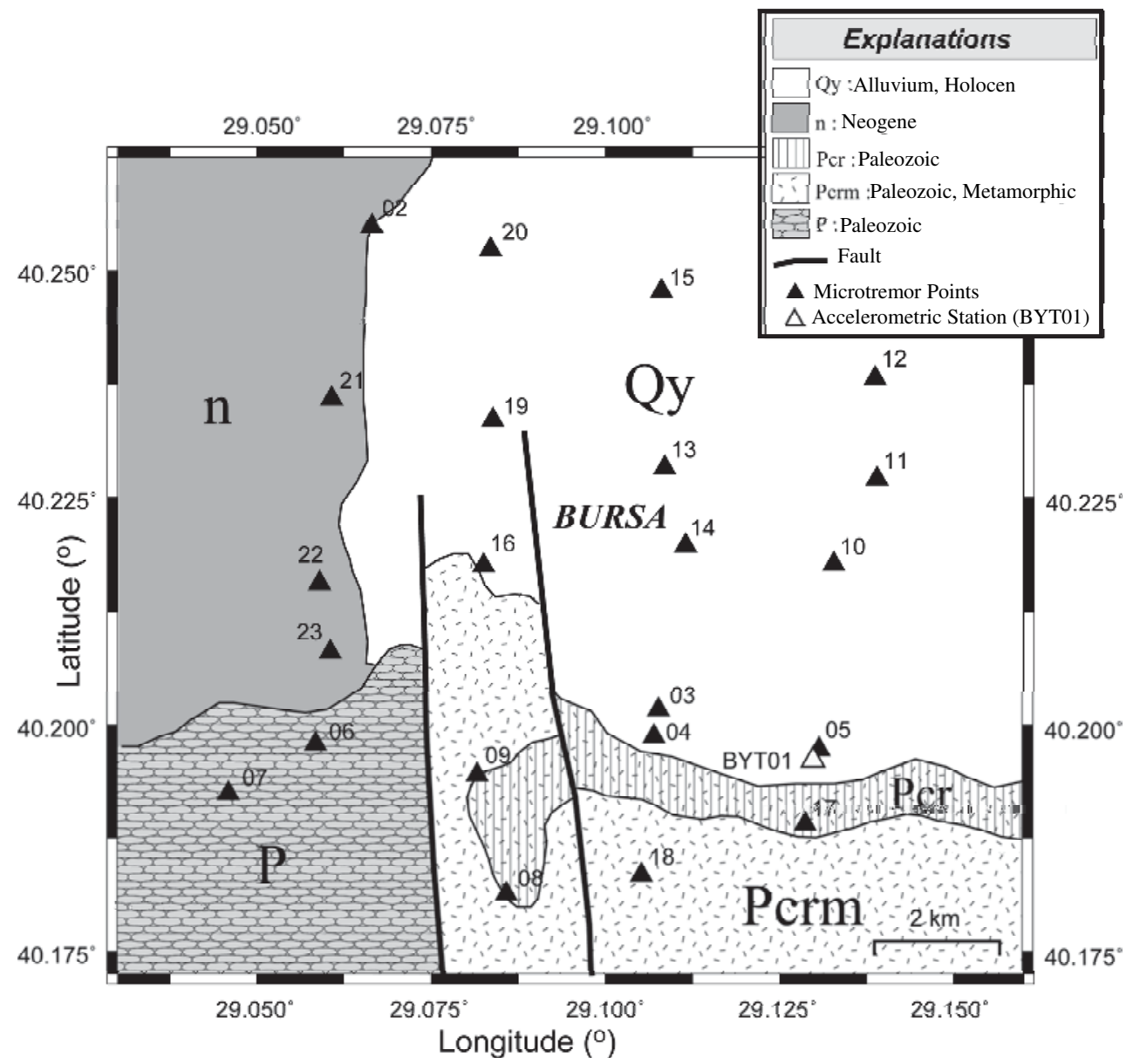

Fig. 2. Simplified geological map of Bursa region. Black triangles indicate points of microtremor measurements; open triangle shows the location of BYT01 station (Modified after MTA, General Directory of Mineral Research and Expolaration).

\section{Method}

The microtremor HVSR method is generally used for microzonation and site responses studies. It considers that the amplification produced by a surface layer can be estimated from the ratio between the horizontal and vertical spectral amplitudes. This method is known as the Nakamura's technique.

The method supposes that microtremors are composed of Rayleigh waves which propagate in a surface layer over a half-space (Dravinski et al., 1996; Lermo \& Chavez-Garcia, 1994). The motion at the interface between the layer and the half-space is not affected by the source effect. Moreover, the horizontal and vertical motions at the interface have similar amplitude due to the ellipticity of the Rayleigh waves. 
Horizontal to Vertical spectral ratio is related to the ellipticity of Rayleigh waves which is frequency dependent (Bard, 1998; Bonnefoy-Claudet et al., 2006). HVSR showes a sharp peak at the fundamental frequency of the sediments, if there is a high impedance contrast between the sediments and the bottom bedrock. Criticism of the HVSR method was often related to the fact that there is no common practice for data acquisition and processing (Mucciarelli \& Gallipoli, 2001). Attempts to provide standards were only made recently (SESAME, 2004). It is widely accepted today that the frequency of the peak of HVSR showes the fundamental frequency of the sediments. Its amplitude depends mainly on the impedance contrast with the bedrock and cannot be used as site amplification. Comparisons with results of standard spectral ratio method have also shown that the HVSR peak amplitude sometimes underestimates the actual site amplification. (Bard, 1998; Gosar \& Martinec, 2009)

\section{Microtremor measurements and analyses}

\subsection{Instruments and data}

A single seismic station was used for the microtremor measurements. It was composed of a three-component seismometer with GPS time, the passing band of this system in DC to 100 $\mathrm{Hz}$. Our sampling was $100 \mathrm{sps}$, reducing the frequency to the band below $50 \mathrm{~Hz}$. We recorded data at 22 different points. Record duration was set to 30 minutes. The mean distance between recording sites is approximately $2 \mathrm{~km}$. The sensors were buried in the ground at each site.

\subsection{HVSR analyses}

Microtremor measurements were made at 22 sites (Figure 2). Their locations were selected to avoid the influence of trees, sources of monochromatic noise, rivers, and strong topographic features. HVSR analysis was performed following SESAME (2004). Recorded time series were visually inspected to identify possible inaccurate measurements and transient pulses. Each record was split in windows between 15 to $30 \mathrm{~s}$ long \% 5 overlapping windows for which amplitude spectra in a range $0.5-20 \mathrm{~Hz}$ were computed using a cosine taper with $10 \%$ smoothing and Konno \& Ohmachi smoothing with a constant of 40 (Konno, \& Ohmachi, 1998). HVSR was then computed as the average of both horizontal component spectra divided by the vertical spectrum for each window. After produced HVSR dominant frequency and maximum amplification were determined. Figures 3 and 4 show an example of the results.

The smallest dominant frequency values $(\leq 2 \mathrm{~Hz})$ were obtained in the northern part of the basin, covered by the thick Neogene and Quaternary sediments (points 19, 21, 22 in Figure 3 and 13, 14, 12 in Figure 4). Frequencies in the range 2 to $4 \mathrm{~Hz}$ were observed on Paleozoic sediments of moderate thickness (points 08, 09, 17 in Figure 3). Dominant frequencies larger than $5 \mathrm{~Hz}$ was obtained on Paleozoic and metamorphic rocks (06, 07 in Figure 3 and 04, 05 in Figure 4). These values are characteristic for most of the Bursa area.

In some cases the microtremor measurements were unable to provide an estimate of dominant frequency (Figure 4). The possible reasons are: wide peak, two or more peaks in a spectrum, flat spectral ratio and very small amplitude of the peak.

Figure 4a shows an example of wide peak that can not be associated to a resonant frequency. Probably due to the several impedance contrasts at various depths, HVSR sometimes resulted in two or more peaks with similar amplitudes. In Figure $4 \mathrm{~b}$, the two peaks are well 
separated in frequency, so it can be the boundary between soft sediments and rock is related to the peak at $1.3 \mathrm{~Hz}$. The second peak at $5 \mathrm{~Hz}$ may be related to Paleozoic rocks. However, in the case shown in Figure 4c, there are two peaks of the same amplitude at $1 \mathrm{~Hz}$ and 13
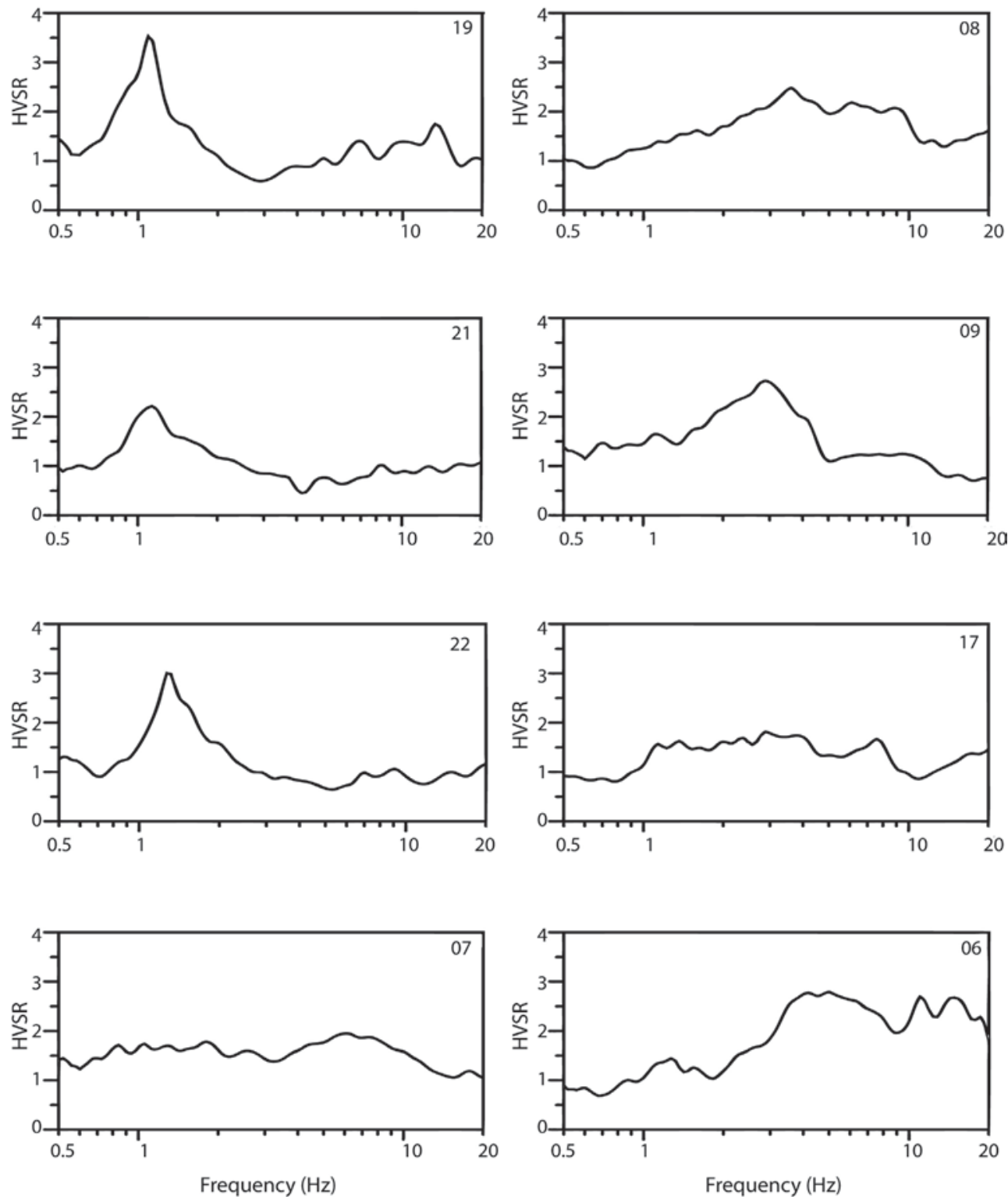

Fig. 3. Examples of HVSR for the measurements points $(06,07,08,09,17,19,21$ and 22) 

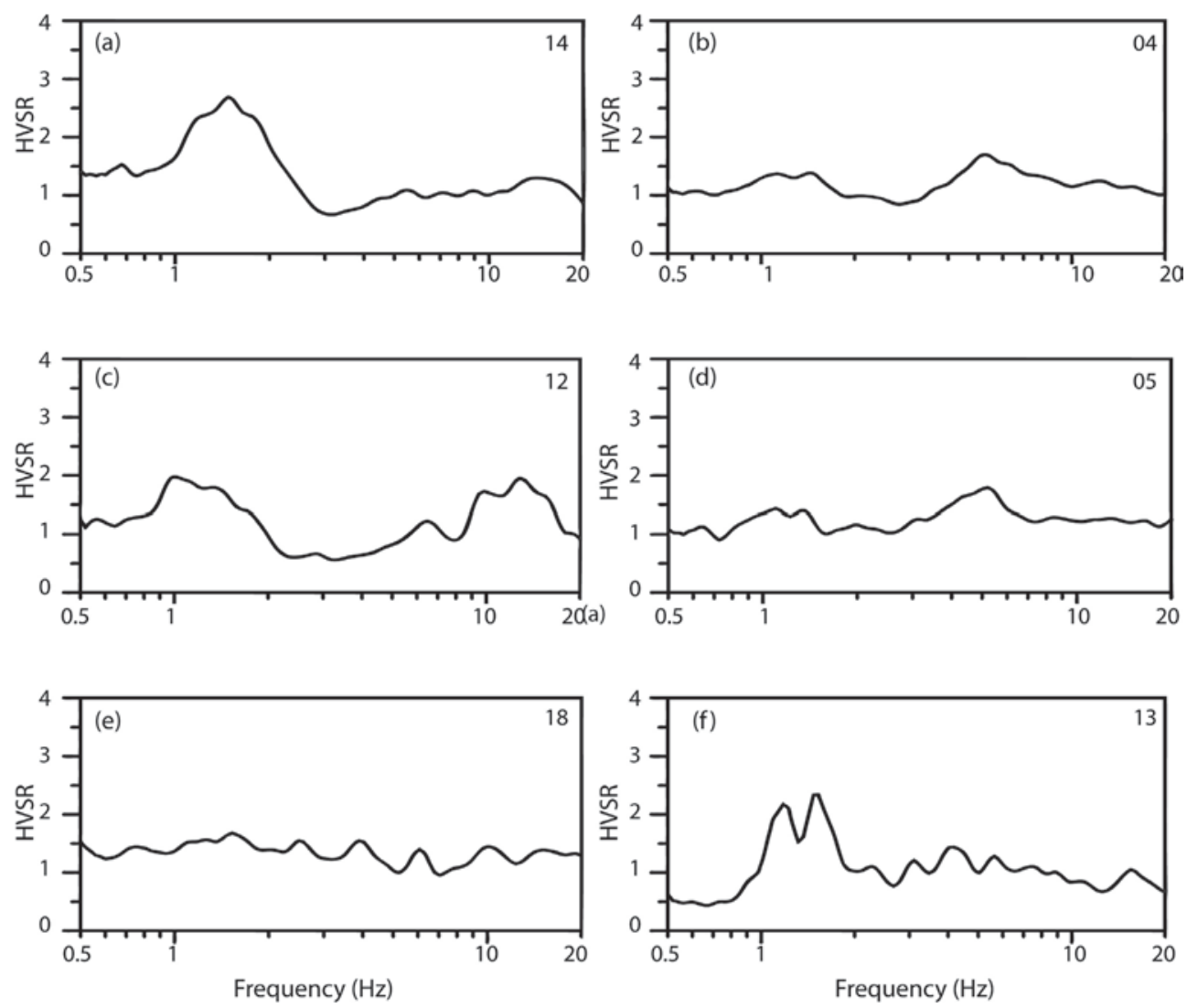

Fig. 4. Some examples of microtremor measurements for which determination of the dominant frequency may be problematic (a) wide peak, (b) two peaks, (c) artificial source of noise, (d) artificial noise which frequency can be determined, (e) almost flat spectral ratio, (f) group of peaks.

Hz. In such cases, we were unable to identify which one corresponds to the most significant geological boundary. Another example (Figure 4d) shows two different peaks at the $1.2 \mathrm{~Hz}$ frequency and $5 \mathrm{~Hz}$. Artificial noise is seen on the first peak but the real peak of HVSR is at a higher frequency $(5 \mathrm{~Hz})$. In some cases, we compared the dominant peak frequency with that from neighbouring measurements with more clear peaks. For some measurements, we obtained almost flat spectral ratios (Figure 4e) with maximum amplitudes smaller than 1.5 $\mathrm{Hz}$. We found no clear peak for this point but it may be correlated with Paleozoic rocks. In Figure $4 \mathrm{f}$, two peaks are observed around $1 \mathrm{~Hz}$. The shape of this HVSR curve indicates that the peak is at a similar frequency, but since it is contaminated with artificial noise, it cannot be accurately identified.The amplitudes of the peaks of HVSR are mostly in the range 1-2 $\mathrm{Hz}$ in Figure 5. Only in a few cases they are larger than $5 \mathrm{~Hz}$. 


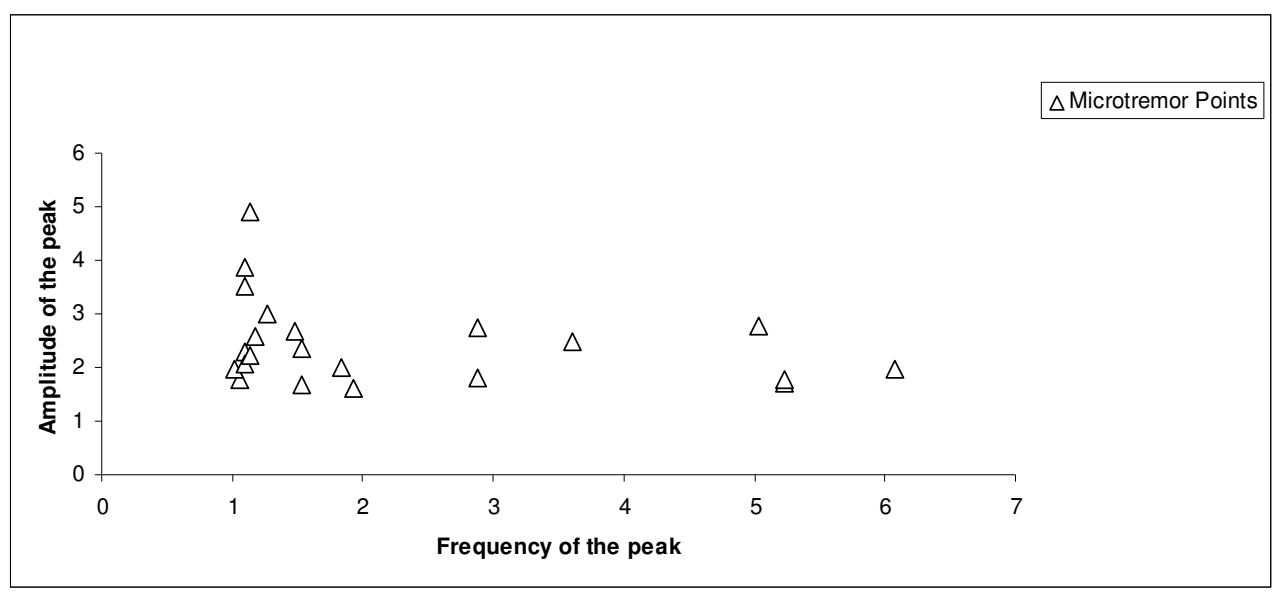

Fig. 5. Amplitude vs. frequency graph of HVSR peaks

\subsection{Time-dependent HVSR}

The common procedure to compute the HVSR spectral ratio relies on average amplitude spectra of the three components of motion. Some researchers such as Almendros et al., (2004) have suggested that this aproach may lead to errors. Perturbations of the wavefield may occur during the recording period and be recorded together with the microtremor data. Usually, these transients are easily identified in the spectra, and the analysis can be performed using only on data windows free of perturbations in order to obtain reliable results. In these cases, artificial peaks appear in the HVSR (Figure 4). These peaks affect the spectral ratio and produce inaccurate results. Because of this problem, time-dependent HVSR has also been used to estimate spectral ratios. This approach consists of compiling HVSR to successive data windows along the traces. This procedure creates several HVSR functions that can be represented a two-dimensional contour plots versus frequency and time. This plot, that is called ratiogram, represents the evolution of the HVSR in the same way that a spectrogram represents the evolution of the spectrum versus frequency and time. (Almendros et al., 2004)

In this study, we selected a window of $25 \mathrm{~s}$ and slided it at intervals of $5 \mathrm{~s}$ along the traces. This length is suitable for the numerical fast Fourier transform (FFT) algorithm for frequencies larger than $0.5 \mathrm{~Hz}$. For each window we calculated the amplitude spectra of the three components using an FFT algorithm, and smoothed it using a cosine window. Frequency-dependent window lengths have also been used keeping a constant number of cycles (Kind et al., 2005). We computed the HVSR separately for all time intervals and plotted them. An example is as a fuction of time shown in Figure 6.

Three component microtremor data was shown in Figure 6a. Using the standard technique, average HVSR are computed from individual windows (Figure 6b). We observed the presence of a dominant peak at about $1.2 \mathrm{~Hz}$ and we can conclude that the site produces amplification for this frequency. Figure $6 c$ shows the time-dependent HVSR which is stationary, at least during particular time periods. An average HVSR could be obtained by stacking the HVSRs. 
(a)

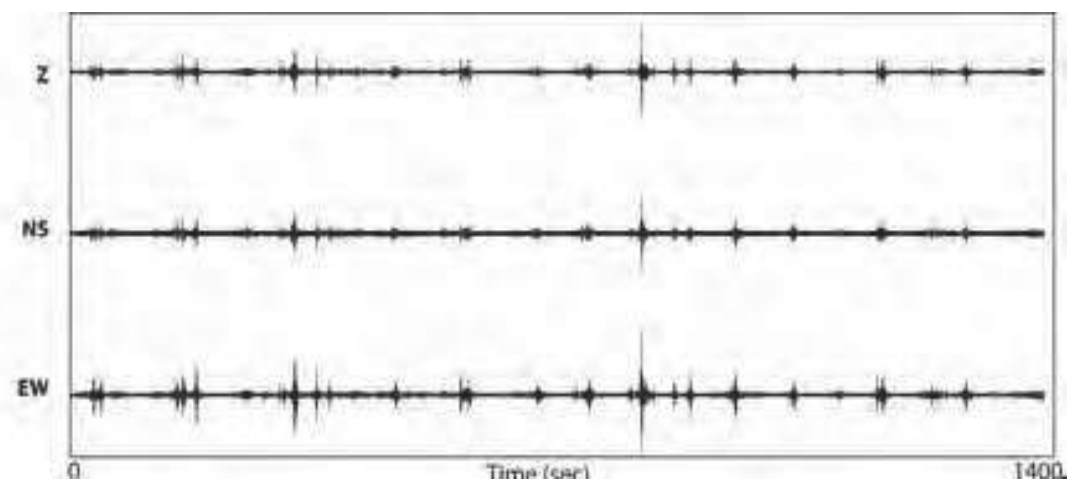

(b)

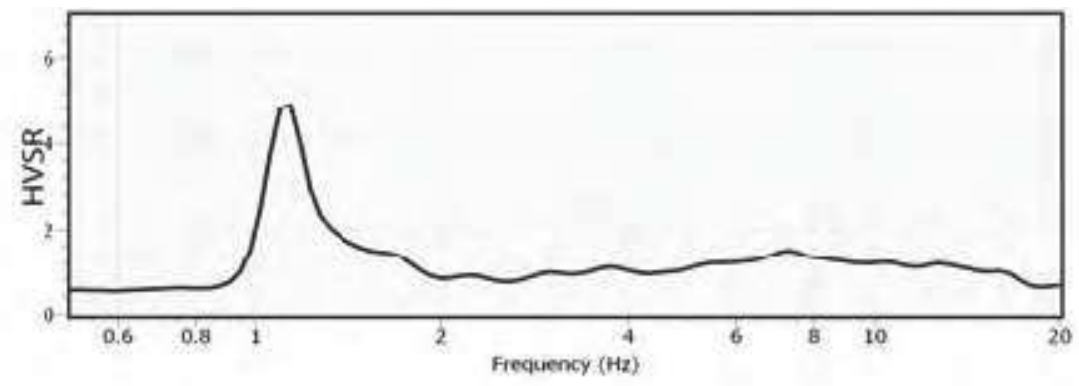

(c)

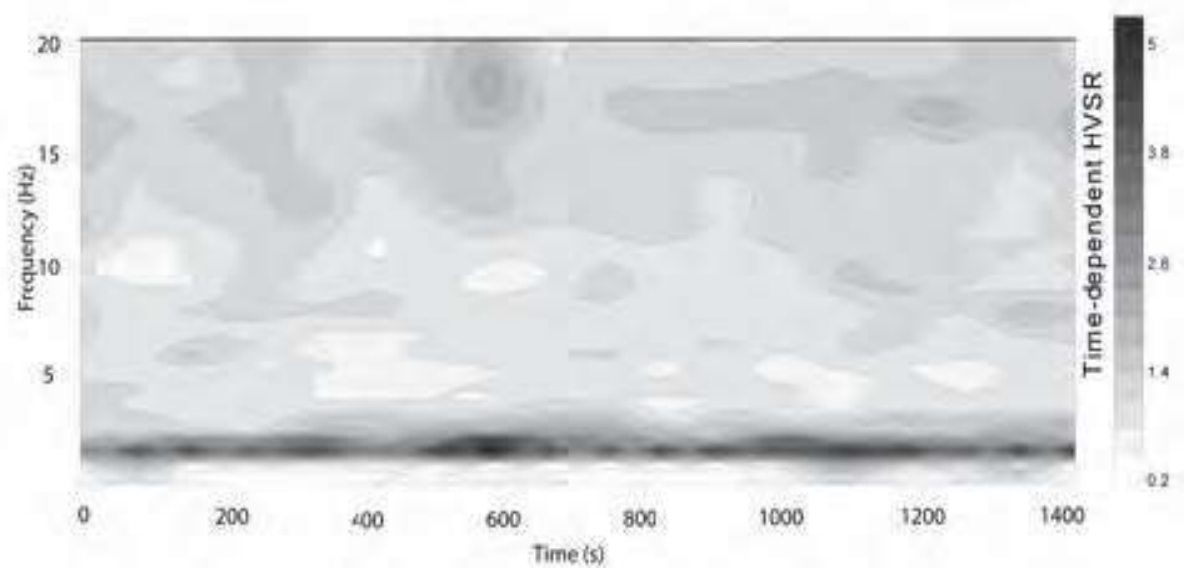

Fig. 6. Example of the application of the time dependent HVSR method (a) three-component microtremor data, (b) average HVSR using standard procedure, (c) ratiogram representing the HVSR as a function of frequency and time.

\section{HVSR results using earthquake data}

Lermo and Chavez-Garcia (1993) presented that the Nakamura (1989) technique could be applied to the S-wave part of the earthquakes, and the HVSR ratios provided amplitude of the soil deposits. We applied the HVSR ratios of the S-wave window for the recorded 
ground motions to sites in the BYT01 for site effect estimation. The Fourier spectrum of ground motion for each event was obtained using the HVSR method.

Earthquake records from an accelerographic station (Figure 2) deployed in the city have been obtained. We used them to compare the results obtained from microtremor survey. A location of the station is given in Table 1.

\begin{tabular}{|c|c|c|c|}
\hline Station Coordinates & $\begin{array}{c}\text { Altitude } \\
(\mathrm{m})\end{array}$ & Recorder Type & Recorder Serial Nr. \\
\hline $\begin{array}{c}40.18240 \mathrm{~N} \\
29.12960 \mathrm{E}\end{array}$ & 193 & Etna & 5035 \\
\hline
\end{tabular}

Table 1. Coordinates of Station BYT01

This station has recorded four shallow earthquakes (depths smaller than $19 \mathrm{~km}$.) with magnitudes (Md) between 3.6 and 5.2. Locations of the events are given in Table 2. Spectral ratios have been computed using the HVSR technique (Figure 7). We have used events for which the signal to noise level is larger than 3 in the frequency range $0.5-20 \mathrm{~Hz}$. The selected window has duration of 15 second beginning 2-3 sec before S-wave arrival. The analysis included a cosine taper before Fourier transform and smoothing with a factor of 40 using the window by Konno \& Ohmachi, 1998.

\begin{tabular}{|c|c|c|c|}
\hline $\begin{array}{c}\text { Earthquake Date } \\
\text { and Time (GMT) }\end{array}$ & $\begin{array}{c}\text { Earthquake } \\
\text { Coordinates }\end{array}$ & Depth & $\begin{array}{c}\text { Magnitude } \\
\text { (Md) }\end{array}$ \\
\hline $20 / 10 / 2006$ & $40.2519 \mathrm{~N}-27.9792 \mathrm{E}$ & 16.7 & 5.2 \\
\hline $24 / 10 / 2006$ & $40.4221 \mathrm{~N}-28.9937 \mathrm{E}$ & 7.9 & 5.2 \\
\hline $25 / 10 / 2006$ & $40.3698 \mathrm{~N}-29.0059 \mathrm{E}$ & 10.7 & 3.6 \\
\hline $19 / 12 / 2006$ & $40.3400 \mathrm{~N}-28.3200 \mathrm{E}$ & 18.5 & 4.2 \\
\hline
\end{tabular}

Table 2. Recorded earthquakes in BYT01 (location parameters were taken from AFAD-ERD).
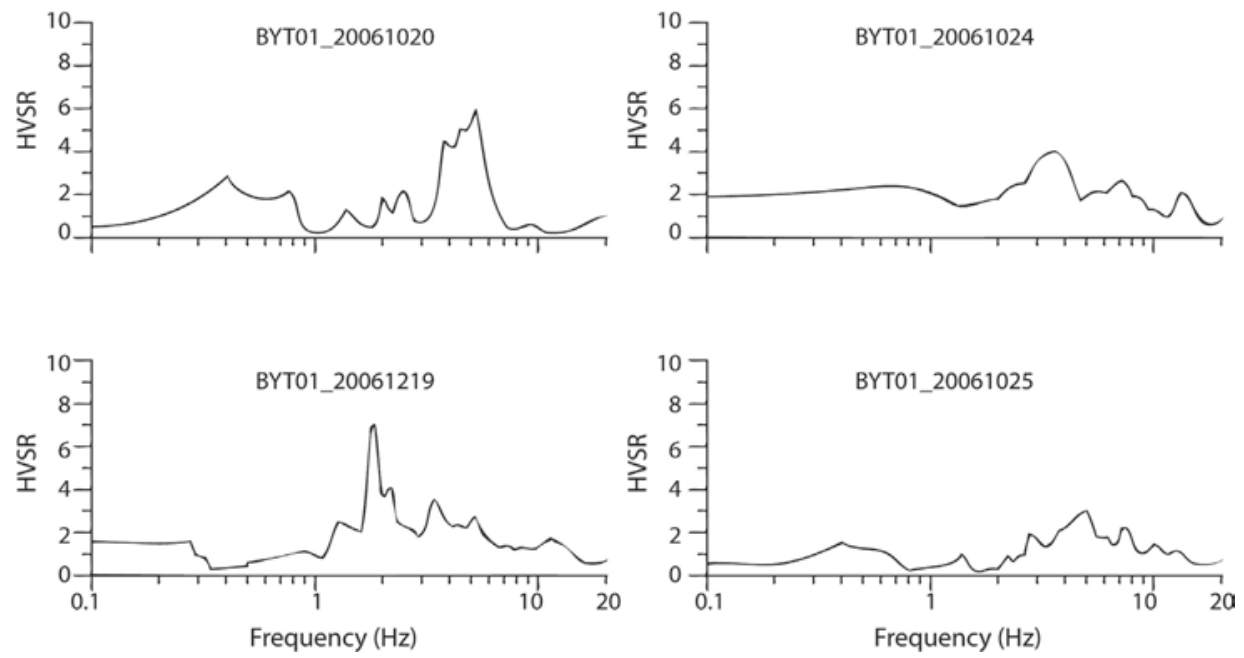

Fig. 7. The HVSR results of four earthquakes.

A dominant frequency around $5 \mathrm{~Hz}$ is observed for events 20061020 and 20061025 in the HVSR results (Figure 7). The BYT01 station is very close to the microtremor point Nr. 05 
which shows on Figure $4 \mathrm{~b}$. We found the dominant frequency at $5 \mathrm{~Hz}$ on point Nr. 05 and these two earthquakes are related to the result of microtremor point and they show similar results. In Figure 7, events 20061024 and 20061219 show different dominant frequency, between $2 \mathrm{~Hz}$ and $4 \mathrm{~Hz}$.

\section{Conclusion and discussion}

The 22 values of dominant frequency and maximum relative amplification (HVSR) were used to draw the contours shown in Figure 8. The contours of dominant frequency values coincide with surficial geology (Figure 8a), the maximum amplification values vary between 1 and 5 (Figure 8b).
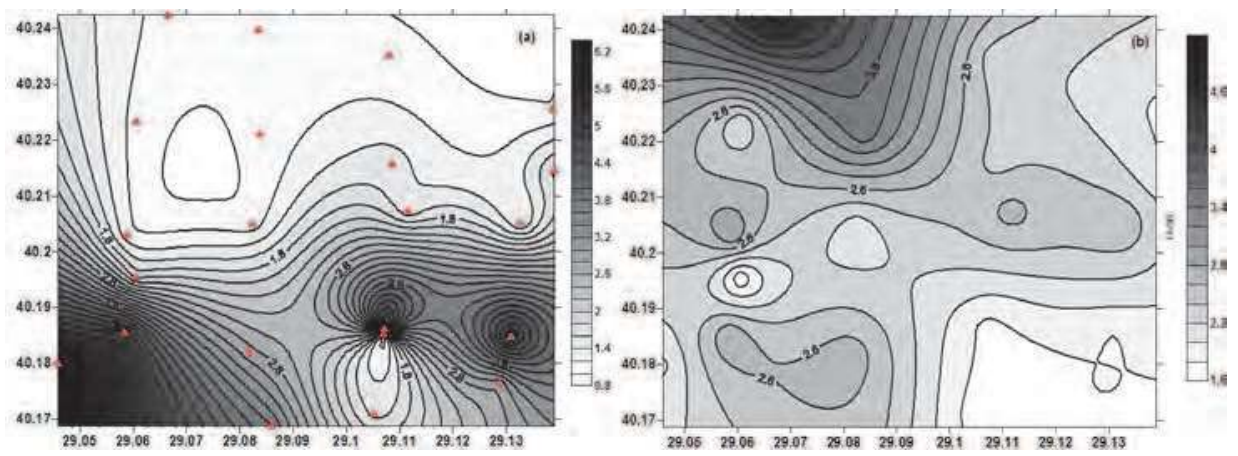

Fig. 8. (a) Dominant frequency and (b) HVSR map of the study area.

Figure 9 shows examples of ratiograms obtained at two different sites. In each case, the top pannel shows the three-components of ambient noise: The bottom pannel shows the calculated ratiogram and the right pannel shows the average HVSR. The gray scale on the right represents the values of the time-dependent HVSR in both ratiograms. In the first case (Figure 9a), the average HVSR does not show a dominant frequency. The flat response is seat with an amplification level approximately equal to one. In the second case (Figure 9b); a clear dominant frequency of $1.2 \mathrm{~Hz}$ appears throughout the duration of the records. Ratiograms like these have been calculated for the entire data set.

In general, the smaller values of dominant frequency show that $(1-2 \mathrm{~Hz})$ correlate with alluvium and Neogene sediments. Peaks at larger frequencies are correlated to Paleozoic and metamorphic rocks. Our measurements show that there are transient zones between different geologic structures (alluvium and Paleozoic rocks).

The map of fundamental soil frequency derived from free-field microtremor measurements should be confirmed by independent information from boreholes, geophysical investigations or earthquake recordings in the future, since the interpretation of microtremors is restricted to identifying the resonance frequency and gives no information on the amplification of seismic ground motion. The HVSR provides an estimate of the bandwidth over which the ground motion is amplified. This is especially important for any microzonation.

Three-component microtremor measurements were conducted at 22 sites in the northern section of the Bursa city, where the different geological structures in the study area outcrop. The fundamental frequencies of the sediments show a range between of 0.5 and $20 \mathrm{~Hz}$. The lower frequencies (below $2 \mathrm{~Hz}$ ) correspond to the Holocene and neogene deposits overlain 
by alluvium, forming a small basin.The higher frequencies correspond to Paleozoic and metamorphic rocks. However, variations over short distances are large.

In addition to microtremor data, earthquake records were also used to compute HVSR. The HVSR analysis of four earthquakes and microtremor at 22 points gives similar results: Dominant frequencies and spectral ratios correlate well with geological structures in the Bursa city.
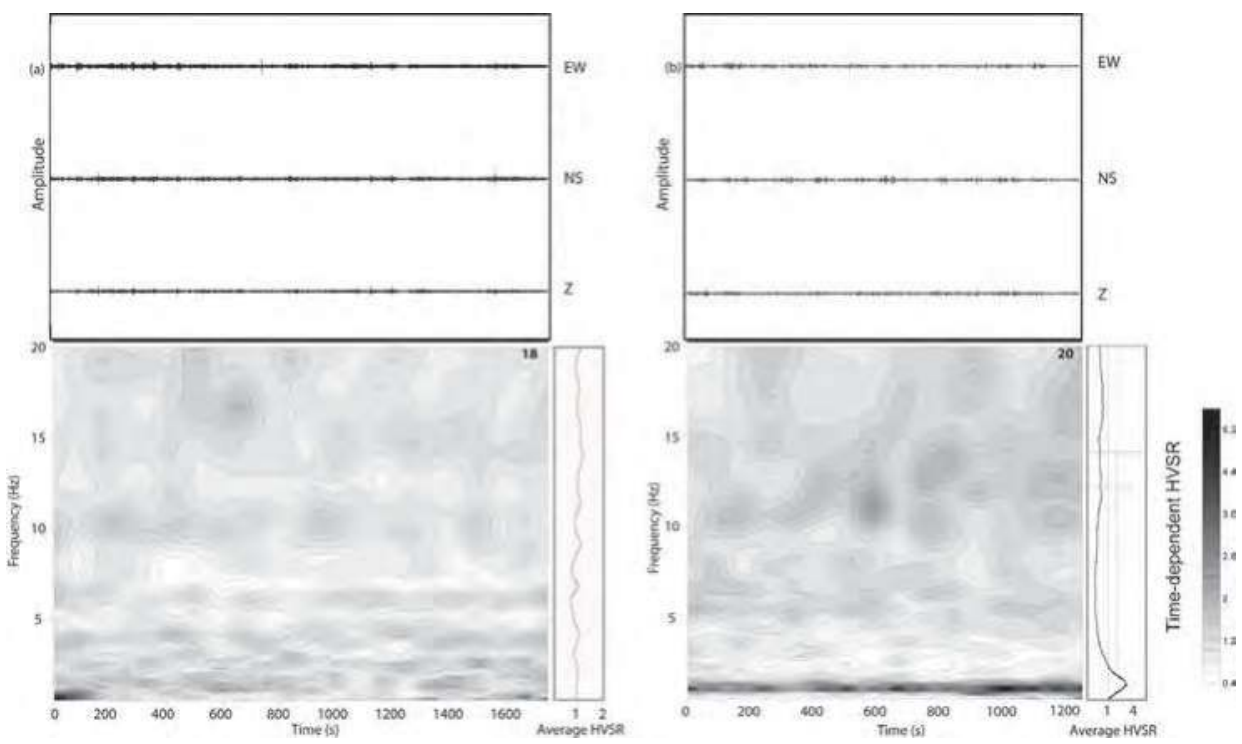

Fig. 9. Two examples of ratiograms and average HVSRs obtained from microtremors recorded at stations a) 18 and b) 20.

Microtremor measurements at 22 points and analysis of contribute valuable preliminary microzonation and site response information. However a more complete study of city-scale earthquake hazard, it is still necessary. More microtremor points and events are necessary to understand site response in Bursa City.

\section{Acknowledgements}

This research is a part of PhD study of Elcin Gok. We thank to the Earthquake Research Department of Presidency of Disaster and Emergency Management Directorate (AFAD) belongs to the Prime Ministry of Turkey for their data support. We also appreciate to Zafer Akcig, Senol Ozyalin and Zulfikar Erhan for facilitating our works in the field. This work was supported by BAP of Dokuz Eylul University (Project Nr. 2006.KB.FEN.007).

\section{References}

Almendros, J., Luzon, F., \& Posadas, A. (2004). Microtremors analysis at Teide Volcano (Canary Islands, Spain): assessment of natural frequencies of vibration using time-dependent horizontal-to-vertical spectral ratios, Pure and Applied Geophysics, 161, 1579-1596.

Bard, P. Y. (1998). Microtremor measurements: A tool for site effect estimation? In Okada \& Sasatani (Eds), Proc. 2nd Intl. Symp. on The Effects of Surface Geology on Seismic Motion, pages 1251-1279. Balkema. 
Bonnefoy-Claudet, S., Cornou, C., Bard, P. Y., Cotton, F., Moczo, P., Kristek, J., \& Fa“h, D. (2006). H/V ratio: A tool for site effects evaluation. Results from 1-D noise simulations. Geophysical Journal International 167, 827-837.

Dravinski, M., Ding, G., \& Wen, K. L. (1996). Analysis of Spectral Ratios for Estimating Ground Motion in Deep Basins. Bulletin Seismological Society of America 86, 646-654.

Field, E.H., \& Jacob, K., (1995). A comparison and test of various site response estimation techniques, including three that are non reference-site dependent. Bulletin Seismological Society of America 85, 1127-1143.

Field E, \& Jacob K. (1993). The theoretical response of sedimentary layers to ambient seismic noise. Geophysical Research Letters, 20 (24), 2925-2928.

Gosar, A. \& Martinec, M. (2009) Microtremor HVSR study of site effects in the Ilirska Bristica town area (S. Slovenia), Journal of Earthquake Engineering 13, 50-67.

Imbach, T., (1997). Geology of Mount Uludag with emphasis on the genesis of the Bursa, Northwest Anatolia, Turkey. In: Shindler, C. \& Pfister, M. (Eds.), In Active Tectonics of Northwestern Anatolia-The Marmara Poly-Project, Hochschulverlag AG an der ETH Zurich-Swiss, p. 239-266.

Kind, F., D. Fah, \& D. Giardini (2005). Array measurements of S-wave velocities from ambient vibrations. Geophysical Journal International, 160, 114-126.

Konno, K. \& Ohmachi, T. (1998). Ground-motion Characteristics Estimated from Spectral Ratio between Horizontal and Vertical Components of Microtremor. Bulletin Seismological Society of America, 88, 228-241.

Lermo, J., \& Chavez-Garcia, F. J. (1993). Site effect evaluation using spectral ratios with only one station Bulletin Seismological Society of America, 83, 1574-1594.

Lermo, J., \& Chavez-Garcia, F. J. (1994). Are microtremors useful in the site response evaluation? Bulletin Seismological Society of America, 84, 1350-1364.

Mucciarelli, M., \& Gallipoli, M. R. (2001). A critical review of 10 years of microtremor HVSR technique. Bolletino di Geofisica Teorica ed Applicata 42, 255-266.

Nakamura, Y. (1989). A method for dynamic characteristics estimation of subsurface using microtremor on the ground surface. Quarterly Report of the Japanese Railway Technical Research Institute (RTRI), 30(1), 25-33.

Ohmachi, T., Nakamura, Y., \& Toshinawa, T. (1991). Ground motion characteristics in the San Francisco Bay area detected by microtremor measurments. In S. Prakash (Ed.), Proceedings of the Second International Conference on Recent Advances in Geotechnical Earthquake Engeneering and Soil Dynamics, March 11-15, St. Louis, Missouri, Univ. of Missouri-rolla, p. 1643-1648.

SESAME, (2004). Guidelines for the implementation of the $H / V$ spectral ratio technique on ambient vibrations: measurements, processing and interpretation, 62 pp.,http://sesamefp5.obs.ujfgrenoble.fr/Delivrables/Del-D23

Suzuki, T., Adachi, Y., \& Tanaka, M. (1995). Application of Microtremor Measurements to the Estimation of Earthquake Ground Motions in Kushiro City during the KushiroOki Earthquake of 15 January 1993. Earthquake Eng. Struct. Dyn. 24, 595-613.

Theodulidis, N. P. \& Bard, P. Y. (1995). Horizontal to Vertical Spectral Ratio and Geological Conditions: an Analysis of Strong Motion Data from Greece and Taiwan (SMART1). Soil Dyn. Earthquake Eng. 14, 177-197.

Topal, T., Doyuran, V., Karahanoglu, N., Toprak, V., Suzen, M.L, \& Yesilnacar, E., (2003). Microzonation for earthquake hazard: Yenisehir settlement, Bursa, Turkey. Engineering Geology, 70, 93-108. 


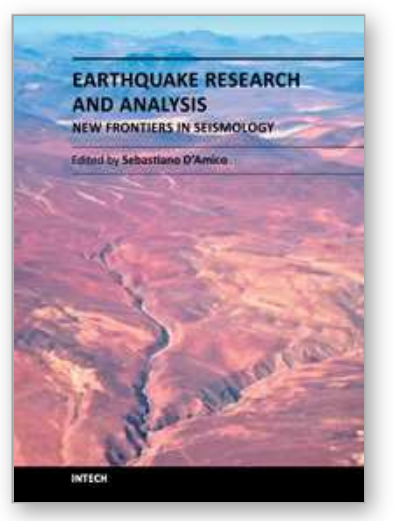

\author{
Earthquake Research and Analysis - New Frontiers in Seismology \\ Edited by Dr Sebastiano D'Amico
}

ISBN 978-953-307-840-3

Hard cover, 380 pages

Publisher InTech

Published online 27, January, 2012

Published in print edition January, 2012

The study of earthquakes combines science, technology and expertise in infrastructure and engineering in an effort to minimize human and material losses when their occurrence is inevitable. This book is devoted to various aspects of earthquake research and analysis, from theoretical advances to practical applications. Different sections are dedicated to ground motion studies and seismic site characterization, with regard to mitigation of the risk from earthquake and ensuring the safety of the buildings under earthquake loading. The ultimate goal of the book is to encourage discussions and future research to improve hazard assessments, dissemination of earthquake engineering data and, ultimately, the seismic provisions of building codes.

\title{
How to reference
}

In order to correctly reference this scholarly work, feel free to copy and paste the following:

Elcin Gok and Orhan Polat (2012). Microtremor HVSR Study of Site Effects in Bursa City (Northern Marmara Region, Turkey), Earthquake Research and Analysis - New Frontiers in Seismology, Dr Sebastiano D'Amico (Ed.), ISBN: 978-953-307-840-3, InTech, Available from: http://www.intechopen.com/books/earthquakeresearch-and-analysis-new-frontiers-in-seismology/microtremor-hvsr-study-for-site-effect-in-bursa-westernanatolia-turkey-

\section{INTECH}

open science | open minds

\section{InTech Europe}

University Campus STeP Ri

Slavka Krautzeka 83/A

51000 Rijeka, Croatia

Phone: +385 (51) 770447

Fax: +385 (51) 686166

www.intechopen.com

\section{InTech China}

Unit 405, Office Block, Hotel Equatorial Shanghai

No.65, Yan An Road (West), Shanghai, 200040, China 中国上海市延安西路65号上海国际贵都大饭店办公楼 405 单元

Phone: +86-21-62489820

Fax: +86-21-62489821 
(C) 2012 The Author(s). Licensee IntechOpen. This is an open access article distributed under the terms of the Creative Commons Attribution 3.0 License, which permits unrestricted use, distribution, and reproduction in any medium, provided the original work is properly cited. 